on the image, reduces its contrast. Light transmission, the percentage of light transmitted in the central portion of the field of view by the optical parts of the telescope, is obviously also of importance in assessing the general performance of the instrument, in addition to field brightness, which gives a measure of the falling-off in illumination towards the edges of the field of view. The booklet describes in some detail the apparatus developed and used at the Laboratory for making measurements of the axial light transmission, the veiling glare index and the field brightness of telescopes and binoculars. The apparatus for the last-named measurement is still in prototype form.

\section{Guide to the British Museum (Natural History)}

I $\mathrm{T}$ is interesting to compare the general format of the publications of the British Museum (Natural History) issued at the present time with those of, say, twenty years ago. Then an austere approach to the subject in strictly traditional covers repelled all but the most ardent of students; but to-day the "Short Guide to the Exhibition Galleries of the Natural History Museum", now in its fourth edition (pp. $28 ; 1956 ; 1 s .6 d$.), is in an attractive coloured and original cover and invites even the least interested in museums to glance at the contents. Following a brief historical introduction, the "Guide" describes in outline contents of the Central Hall and its five bays. Attention is then directed to a set of cases introducing the five Departments of the Museum-Zoology, Entomology, Geology, Mineralogy and Botany. 'The reader is quickly led through the Departments, and the special features of each are described in a few-in some cases dramatic-words. The "Guide" includes a table giving the geological time-scale and some general information concerning the Museum and its main activities. This indeed is a booklet which can be used equally as a guide during a visit to the Museum and afterwards as a reminder of the objects seen.

\section{The Gila Monster of North America}

THE Helodermatidae are marked off from other lizards by the possession of grooved teeth in the lower jaw and of poison glands. The most widely known species is the gila monster, about which a number of myths and tales have gathered. Charles $M$. Bogert and Rafael Martin del Campo have made an exhaustive investigation into the natural history and ecology of the family and produced an interesting memoir (Bull. American Mus. Nat. Hist., 109, 238+20 plates; $1956 ; 4$ dollars). It does not deal with the anatomy except for a brief reference to the lower jaw, the arrangement of the bones of which provide a specific differentiation. The authors recognize two distinct species, Heloderma horridum and $H$. suspectum, which are distinguishable by definite external characters and have different distributions. H. horridum with three subspecies, each occupying its own area, is found on the Pacific drainage of Mexico, and it is suggested that it should be called the beaded lizard from the characteristic appearance of the skin : it is known in Mexico as the escorpion. It was first mentioned by Hernández in 1615 . The other and better-known form is the gila monster, $H$. suspectum with two subspecies, found from just inside Mexico northwards into central Arizona. It has been shown experimentally that heloderms secrete a poison that is quite lethal to a wide range of animals including the common laboratory types. The authors have traced thirty-four recorded cases of gila monsters having bitten human beings, and in eight of these death was stated to have followed; but the actual records are not satisfactory, and in some there were contributory factors. The possibility cannot be ruled out, but the poison mechanism is not efficient, and it is probable that only in exceptional conditions could sufficient poison be injected to prove fatal. In the chapter dealing with myths there is an amusing tilt at the ardent systematist in the setting up of a genus Sampoderma for a creature described by a Mr. Holmes and a Dr. Watson from a locality near Baker Street.

\section{Overseas Students at British University Institutions}

AppendIx III of the 1956 "Yearbook of the Universities of the Commonwealth" gives the number of overseas students enrolled for full-time study or research in British universities and university colleges at the beginning of the academic year 1954 55 as 9,050 , of whom 1,261 were women, compared with 8,619 in $1953-54$ and 6,264 in $1938-39$. Of these, 5,575 came from other parts of the British Commonwealth, including 346 from Australia, 372 from Canada, 238 from the Gold Coast, 1,229 from India, 173 from New Zealand, 700 from Nigeria, 319 from Pakistan, 193 from Malaya (with 60 more from Singapore) and 491 from South Africa. Arts claimed 3,741 students, technology 1,799 , medicine 1,597 , pure science 1,316 , dentistry 311 , agriculture and forestry 214, and veterinary science 72. Excluding external students, London had 3,454 overseas students, Cambridge 820, Oxford 855, Edinburgh 683 ; but of the rest only Durham (356), Leeds (348), Manchester (393) and Glasgow (313) had more than three hundred. Outside the Commonwealth, the United States provided 820 students, and Egypt 306.

\section{Guide to the Manchester Libraries}

THE North-Western Group of the Reference and Special Libraries Section of the Library Association has published, under the title "The Libraries of Greater Manchester" (pp. 92; 1956; 15s.), a guide to the resources and special eollections of the region which both shows the wealth of recerded information available in the area and also the appropriateness of Manchester on this count alone as a regional centre if the Government ever attempts to develop a national library system, at least for science and technology. As Mr. L. L. Ardern, chairman of the North-Western Group, explains in an introduction, the guide is based on the 141 returns received to a questionnaire which was sent to all likely societies. Mr. Harold Smith's editing has provided a work which is both clear and concise and should enable the student or expert seeking information to decide readily which of the many libraries of the area is most likely to be able to help him ; at the same time, it should mininize the chance of a library being troubled with a request which it is unable to meet by reason of its holdings and scope or on constitu. tional grounds. The guide is well produced and should materially assist in library co-operation and the more effective use of regional resources.

\section{The Night Sky in October}

New moon occurs on Oet. 4d. 04h. 24m., U.T., and full moon on Oct. 19d. 17h. 24m. The following conjunctions with the Moon take place: Oct. ld. 02h., Venus $5^{\circ}$ N. ; Oct. 2d. 18h., Jupiter $6^{\circ}$ N.; 